\title{
Micropatterned Poly(ethylene glycol) Islands Disrupt Endothelial Cell-Substrate Interactions Differently from Microporous Membranes
}

\author{
Zahra Allahyari $^{\dagger, \ddagger}$, Shayan Gholizadeh ${ }^{\dagger} \neq$, Henry H. Chung ${ }^{\ddagger}$, Luis F. Delgadillo§, Thomas R. \\ Gaborski ${ }^{*},+\ddagger, \S$ \\ †Department of Microsystems Engineering, Rochester Institute of Technology, 160 Lomb \\ Memorial Drive, Rochester, NY 14623, USA \\ ‡Department of Biomedical Engineering, Rochester Institute of Technology, 160 Lomb Memorial \\ Drive, Rochester, NY 14623, USA \\ §Department of Biomedical Engineering, University of Rochester, 201 Robert B. Goergen Hall, \\ Rochester, NY 14627, USA
}

\begin{abstract}
Porous membranes are ubiquitous in cell co-culture and tissue-on-a-chip studies. These materials are predominantly chosen for their semi-permeable and size exclusion properties to restrict or permit transmigration and cell-cell communication. However, previous studies have shown pore size, spacing and orientation affect cell behavior including extracellular matrix production and migration. The mechanism behind this behavior is not fully understood. In this study, we fabricated micropatterned non-fouling polyethylene glycol (PEG) islands to mimic pore openings in order to decouple the effect of surface discontinuity from potential grip on the vertical contact area provided by pore wall edges. Similar to previous findings on porous membranes, we found that the PEG islands hindered fibronectin fibrillogenesis with cells on patterned substrates producing shorter fibrils. Additionally, cell migration speed over micropatterned PEG islands was greater than unpatterned controls, suggesting that disruption of cell-substrate interactions by PEG islands promoted a more dynamic and migratory behavior, similarly to enhanced cell migration on microporous membranes. Preferred cellular directionality during migration was nearly indistinguishable between substrates with identically patterned PEG islands and previously reported behavior over micropores of the same geometry, further confirming disruption of cellsubstrate interactions as a common mechanism behind the cellular responses on these substrates. Interestingly, compared to respective controls, there were differences in cell spreading and a lower increase in migration speed over PEG islands compared prior results on micropores with identical feature size and spacing. This suggests that membrane pores not only disrupt cell-substrate interactions, but also provide additional physical factors that affect cellular response.
\end{abstract}

*Corresponding Author: thomas.gaborski@rit.edu; twitter: @tgaborski;

Author Contributions

The manuscript was written through contributions of all authors. All authors have given approval to the final version of the manuscript

Supporting Information. Optimization of PLL-g-PEG concentration and coating time for coating protocol, confirmation of PLL-gPEG coating stability under acetone washing, Large field of view AFM 2D phase image and 3D height profile of the PLL-g-PEG patterned substrate. 


\section{Graphical Abstract}

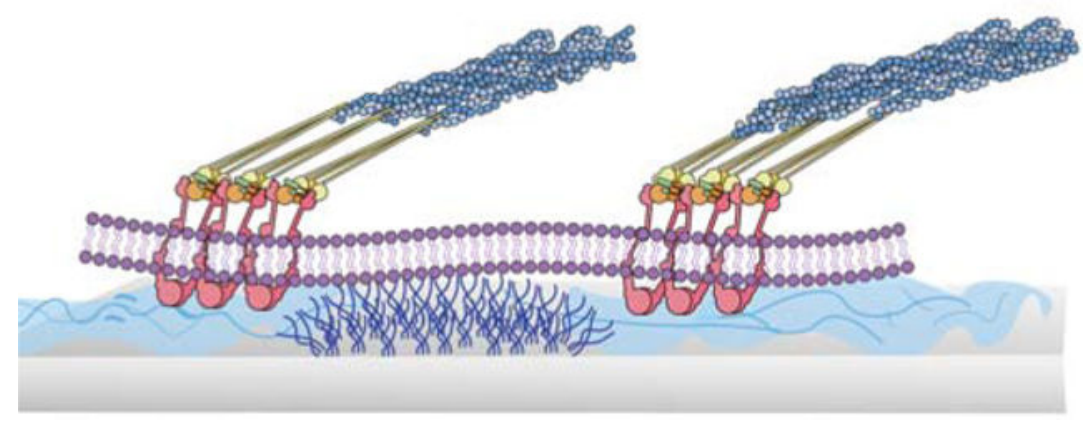

\section{Keywords}

Cell spreading; cell migration; fibronectin; polyethylene glycol; porous membrane; cell-substrate interactions

\section{INTRODUCTION}

The interest in co-culture systems, barrier models and organ-on-a-chip studies stems from their application in drug discoveries and disease models as well as understanding of cell-cell communication at tissue interfaces. ${ }^{1,2}$ Due to the capabilities of porous membranes in providing biologically relevant cell-cell interactions between the co-cultured cells, these membranes have received significant attention in development of biomimetic platforms to model different tissue and organs including lung, blood brain barrier, kidney, blood vessel, gut, and liver. ${ }^{3-11}$ While these membranes effectively support cell-cell communication, their role in cellular behaviors including cell migration, extracellular matrix (ECM) development, and cell adhesion is not fully understood and is currently under study.

The role of porous membranes in the change of migratory behavior and ECM formation for human umbilical vein endothelial cells (HUVECs) was previously studied by our group, and it was shown that substrate disruption can lead to production of shorter fibrils and faster cell migration on porous membranes as compared to non-porous controls. ${ }^{12,13}$ It was concluded that the inverse relationship between fibronectin fibrillogenesis and speed of migration suggests that development of shorter fibrils on a disrupted surface can enable quicker cell migration, or conversely faster migration may hinder fibril elongation. Understanding this inverse relationship is important since if a strong and well developed ECM underneath a new endothelial sheet in a tissue construct is required, the cells should spread more slowly across the substrate, however if faster vascular coverage is necessary, it is achievable at the cost of having less extracellular matrix which may compromise future stability. Although the enabling mechanism for these findings is not fully understood, it was previously suggested that the pore openings which create the surface disruption play a critical role in the regulation of these behaviors.

Still there is an unanswered question of whether surface disruption due to the pore opening is the only contributing factor in altering migratory behavior of cells on a porous membrane, 
or whether pore edges should also be considered as a determinative factor for regulation of cell migration and spreading on a porous membrane. Pore edges which can provide increased vertical contact area for cell adhesion and migration has not been previously investigated as a separate contributing factor in studies involving porous membranes. Additionally, there is a growing interest in utilizing microposts to mimic cellular microenvironment in terms of mechanical cues. These studies demonstrate how flexibility of microposts can regulate cell spreading and migratory behavior of cells through modulating substrate rigidity. ${ }^{14-18}$ However, similar to the role of pores in porous membranes, pillar walls can be considered as potential gripping points for cells, and this topological aspect of microposts can influence cell migration and spreading in addition to the substrate rigidity effect. Therefore, it is important to study pore edges or pillar walls as a contributing factor for the aforementioned changes in cellular behavior, particularly on porous membranes which are used in an ever-increasing number of scientific studies.

The aim of this study was to decouple the effect of pore edges and pore openings on a porous membrane through a non-fouling micropatterned substrate. We generated a nonfouling micropattern on a silicon dioxide $\left(\mathrm{SiO}_{2}\right)$ substrate, which resembles pore openings in a porous membrane in terms of shape, size and pattern of disruption, but without any pore edges. $3 \mu \mathrm{m}$ diameter pore size was chosen because it is a commonly used pore size for membranes in the barrier model community and because it is large enough to allow leukocyte transmigration, while small enough to generally prevent endothelial transmigration. ${ }^{2,12,19-22}$ In order to create the non-fouling regions in the patterned substrate, Poly(L-lysine)-g-poly(ethylene glycol) (PLL-g-PEG) was utilized, which has been shown as a suitable candidate for generation of such non-fouling patterns in previous studies. ${ }^{23-30}$ The PLL backbone of this polymer allows effective adsorption onto negatively charged surfaces such as $\mathrm{SiO}_{2}$, while PEG branches hinder cell adhesion to the coated substrate. ${ }^{23,24,28}$ Stamp microcontact printing and deep UV laser ablation are commonly applied chemical patterning methods for developing such a micropatterned substrate, however as for every patterning technique they have some limitations including low reproducibility due to stamp degradation and low resolution due to the incomplete polymer ablation. ${ }^{24,31,40,41,32-39}$ In the current work, we combined photolithography and simple surface adsorption of the PLL-g-PEG polymer to make a reproducible pattern with fewer steps and without the aforementioned complications to provide high-resolution micropatterning. The created micropatterned substrate was used to study FN fibrillogenesis, migratory behavior, and spreading of endothelial cells. It was demonstrated that while endothelial cells showed similar trends of changes in FN fibrillogenesis and migration speed as compared to prior results on porous substrates, differences in cell spreading and a lower increase in migration speed were observed on these substrates compared to prior results over micropores. Our studies suggest there are additional physical factors of micropores resulting in these slight differences in behavior in addition to the disruptive nature of the open pores. 


\section{METHODS}

\subsection{Optimization of the PLL-g-PEG coating on $\mathrm{SiO}_{2}$ substrate}

$\mathrm{SiO}_{2}$ substrates were prepared using conventional microfabrication techniques similar to our previous works. ${ }^{12,13,42}$ Briefly, a $300 \mathrm{~nm}$ layer of $\mathrm{SiO}_{2}$ was prepared by plasma enhanced chemical vapor deposition (PECVD). In order to achieve non-fouling substrates, PLL(20)g(3.5)-PEG(2) (Nanosoft Biotechnology LLC) was used, in which 20 represents a PLL backbone of $20 \mathrm{kDa}, 3.5$ is the grafting ratio and 2 corresponds to the PEG side chains of 2 kDA. ${ }^{43}$ To achieve high-density PLL-g-PEG grafting which effectively prevents cell adhesion, different concentrations of PLL-g-PEG in 10mM HEPES solution ranging from 0.1 to $0.9 \mathrm{mg} / \mathrm{ml}(0.1,0.3,0.5,0.7$, and $0.9 \mathrm{mg} / \mathrm{ml})$ were placed dropwise on $\mathrm{SiO}_{2}$ substrate for different periods of time ranging from 30 to 115 minutes with increments of 15 minutes. After these periods of time, the solution was removed and the substrates were immediately washed before they dried. For quantification of PLL-g-PEG coating under each condition, $0.1 \mathrm{mg} / \mathrm{ml}$ fluorescent bovine serum albumin (f-BSA) was introduced to each substrate and was washed after $1 \mathrm{~h}$. Prevention of BSA adsorption on $\mathrm{SiO}_{2}$ substrate was considered as a criterion for density of PLL-g-PEG grafting on the surface. The adsorbed f-BSA on the surface was quantified based on the florescent intensity of each surface using a Keyence BZX700 microscope (Keyence Corp. of America, MA, USA). Non-labeled BSA was also introduced on the $\mathrm{SiO}_{2}$ substrate and measured intensity was considered as the background intensity. The $\mathrm{SiO}_{2}$ surface without PLL-g-PEG coating was considered as the negative control and its measured intensity after introducing f-BSA was used for normalizing the measured values.

\subsection{Development of non-fouling micropattern on $\mathrm{SiO}_{2}$ substrate}

Photolithography steps were followed to obtain a non-fouling micropattern on the $\mathrm{SiO}_{2}$ layer with a similar pattern to our previous porous membranes. ${ }^{12,13}$ MicroPrime MP-P20 was utilized as adhesion promoter on top of the $\mathrm{SiO}_{2}$ layer. Microposit@ $\mathrm{S} 1813$ positive photoresist was spin-coated at $3000 \mathrm{rpm}$ for $45 \mathrm{~s}$, followed by a soft bake step on a hotplate at $115^{\circ} \mathrm{C}$. GCA $6000-$ Series DSW $5 \mathrm{X}$ g-line stepper was used to expose the photoresist layer with a $150 \mathrm{~mJ} / \mathrm{cm} 2$ exposure energy through a soda lime mask to obtain $3 \mu \mathrm{m}$ pores in the photoresist with $6 \mu \mathrm{m}$ center-to-center spacing in a hexagonal arrangement. The same method of lithography and the same mask was previously used for creating the pores in our porous membranes to have the highest consistency with our previous works. ${ }^{12,13}$ The exposed wafer was developed in MF CD-26 developer for $1 \mathrm{~min}$, followed by washing with deionized water for $5 \mathrm{~min}$. Hard bake was performed for $1 \mathrm{~min}$ at $150{ }^{\circ} \mathrm{C}$. The optimum coating process which was obtained in the previous step was applied for PLL-g-PEG coating after lithography process. PLL-g-PEG solution in the optimum concentration was placed on the patterned photoresist for the optimum period of time. Then, the PLL-g-PEG solution was removed, the substrate was washed twice immediately, photoresist was removed using acetone, and the substrate was washed again with DI water. The process flow is presented in Figure 1A. The non-fouling micropattern was visualized using f-BSA coating on patterned substrates using Keyence BZ-X700 microscope (Figure 1D). It should be noted that the stability of PLL-g-PEG coating under acetone washing had been also evaluated by 
comparison between f-BSA adsorption on PLL-g-PEG coated substrates with and without acetone washing in the earlier step.

\subsection{Atomic Force Microscope (AFM)}

The PLL-g-PEG patterned substrates were examined using an MFP-3D AFM (Oxford Instruments). TR800PSA cantilevers (Oxford Instruments) with a spring constant of 0.15 $\mathrm{N} / \mathrm{m}$, were utilized to scan the surface in tapping mode.

Briefly, the sample was prepared, mounted onto a fluid cell chamber, and PBS were added on top of the sample to prevent PEG brushes from collapsing onto the substrate. Surface topography scans were taken with a scan speed of $0.5 \mathrm{~Hz}$ to minimize imaging artifacts over a fixed area. The heights of the PEG brushes were calculated from the height profile measured across the image.

\subsection{Cell culture}

Pooled human umbilical vein endothelial cells (HUVECs) were cultured in M200 with 2\% Large Vessel Endothelial Supplement (LVES) and 1\% penicillin and streptomycin. HUVECs and all of the cell culture reagents were purchased from Thermo Fisher Scientific (Waltham, MA, United states) unless stated otherwise. HUVECs were detached by TrypLE and seeded on samples in the density of $6 \times 10^{3}$ cells $/ \mathrm{cm}^{2}$. Cells were used between passages 3-5.

\subsection{Cell adhesion and morphology on PLL-g-PEG coating}

Preliminary experiments were required to verify that the developed coating method is effective, and PLL-g-PEG coating is efficiently non-fouling for cells. Since cells are able to attach to the uncoated areas of the patterned samples, HUVECs were instead seeded on fully PLL-g-PEG coated $\mathrm{SiO}_{2}$. HUVECs were also seeded on fully PLL-g-PEG coated $\mathrm{SiO}_{2}$ which were incubated at $37^{\circ} \mathrm{C}$ for $24 \mathrm{~h}$ prior to cell seeding to evaluate the stability of the coating in cell culture condition. Uncoated $\mathrm{SiO}_{2}$ was used as the negative control.

Live/Dead viability assay was performed $24 \mathrm{~h}$ after cell seeding using calcein AM and ethidium homodimer-1 (EthD-1). Briefly, samples were washed with PBS and $10 \mu \mathrm{L}$ of working solution containing $2 \mu \mathrm{M}$ calcein AM and $4 \mu \mathrm{M}$ EthD-1 in the cell culture medium was added to each sample. Working solution was removed after $15 \mathrm{~min}$ and $10 \mu \mathrm{L}$ of cell culture medium was added to each sample, and since samples were on nontransparent $\mathrm{Si}$ wafer, they were inverted on the glass coverslips for fluorescence imaging. Silicone spacers were used to avoid direct contact between the samples and the glass coverslips. Images were obtained at 40X magnification with a Keyence BZ-X700 microscope through GFP and Texas RED filters for visualization of calcein AM and EthD-1, respectively.

\subsection{Cell spreading and F-actin formation}

Cells were seeded on the PEG islands and control $\mathrm{SiO}_{2}$ substrates for $24 \mathrm{~h}$, then fixed in $3.7 \%$ formaldehyde for $15 \mathrm{~min}$, and washed with PBS. This was followed by cell permeabilization for $3 \mathrm{~min}$ in $0.1 \%$ Triton X-100 and washing with double-distilled water. To visualize nuclei and stress fibers, HUVECs were stained using DAPI (300 nM) and 1:400 AlexaFluor 488 conjugated phalloidin for 3 and 15 minutes, respectively. Cells were washed 
and $10 \mu \mathrm{L}$ PBS was added to each sample, and the samples were flipped on a glass coverslip. Images were captured at 40X magnification through DAPI and GFP filters on a Keyence BZ-X700 microscope. Area of spreading and intensity of actin fibers were measured for each cell by ImageJ software. Intensity of actin fibers were normalized by subtracting the background intensity.

\subsection{Tight junction formation}

Cells were seeded in the density of $25 \times 10^{3}$ cells $/ \mathrm{cm}^{2}$ on the PEG islands and control $\mathrm{SiO}_{2}$ samples to reach confluence in a short time interval. After $96 \mathrm{~h}$ of the seeding, cells were fixed with $3.7 \%$ formaldehyde for $15 \mathrm{~min}$, permeabilized with $0.1 \%$ Triton X-100 for $3 \mathrm{~min}$, and blocked with $40 \mathrm{mg} / \mathrm{ml} \mathrm{BSA}$ for $15 \mathrm{~min}$. Then, the cells were stained using 1:100 AlexaFluor488 conjugated anti-ZO-1/TJP1, Clone ZO1-1A12 for $2 \mathrm{~h}$. HUVECs were washed twice with PBS after each step. The tight junctional proteins, ZO-1, were then visualized at 40X magnification through GFP filters on a Keyence BZ-X700 microscope.

\subsection{Fibronectin fibrillogenesis}

Fibronectin fibrillogenesis was also evaluated on the PEG islands and control $\mathrm{SiO}_{2}$ samples. After cell culture for $24 \mathrm{~h}$, cells were fixed with $3.7 \%$ formaldehyde for $15 \mathrm{~min}$ and washed with PBS, then blocked with $20 \mathrm{mg} / \mathrm{ml} \mathrm{BSA}$ for $15 \mathrm{~min}$ and again washed with PBS. In the next step, cells were stained using 1:100 dilution of AlexaFluor 488 conjugated antifibronectin, Clone FN-3 for $2 \mathrm{~h}$ and washed with PBS three times. PBS were added to the samples and they were flipped on glass coverslips. Images were obtained at $40 \mathrm{X}$ magnification through a GFP filter on a Leica DMI6000 microscope (Leica Microsystems, Buffalo Grove, IL), and the lengths of fibrils were measured using a custom-written MATLAB algorithm (freely available on GitHub: https://github.com/gaborskilab). Briefly described, a disk filter with a 10-pixel radius was applied to the original image to create a background image, which was then subtracted from the original image to correct for nonuniform lighting. A Laplacian of Gaussian (LoG) filter was then applied to the backgroundcorrected image to identify the edge of each fibronectin fibril. The half perimeter of the identified edge was reported as the fibril length.

\subsection{Migration Assay}

HUVECs were seeded on the PEG islands and control $\mathrm{SiO}_{2}$ substrates for $3 \mathrm{~h}$ and then flooded with cell culture medium containing 1:1000 dilution of SiR-DNA (Cytoskeleton Inc, Denver, CO). An additional hour was required for cells to uptake SiR-DNA to be trackable through SiR-DNA probe using Leica DMI6000 microscope. Then, time-lapse imaging was performed every 15 minutes for 24 hours to track cell migration as described in our previous works. ${ }^{13,44} 97$ frames were captured from each set stage and migration was evaluated using a custom-written MATLAB algorithm (freely available on GitHub: https:/github.com/ gaborskilab). Briefly, a disk filter with a 10-pixel radius was applied to the original image to create a background image, which was then subtracted from the original image to correct for non-uniform lighting. The background-corrected image was then binarized into black and white based on fluorescent intensity (any pixel that had fluorescent intensities greater than one standard deviation above the mean was considered to be part of a cell nucleus). The centroid positions of the cell nucleus from two consecutive time points defined each "step" 
of cell migration. The direction of each step takes on a value between 0 and $360^{\circ}$. The average speed of each cell was obtained by taking the ratio of the total distance traveled and the total duration of travel.

\subsection{Statistical analysis}

For statistical analysis, two-tailed student's t-test was used for data with Gaussian distributions and Mann-Whitney test was performed for the rest of the data. For box plots, each box includes data from 25 th to 75 th percentile, and the middle line shows median. The whiskers are extended to the lowest/highest values within minus/plus 1.5 times interquartile range (IQR). Sample sizes are noted in each figure legend.

\section{RESULTS AND DISCUSSION}

\subsection{Development of a Non-Fouling Micropattern on $\mathrm{SiO}_{2}$ Substrates}

In order to generate a non-fouling micropatterned substrate, we implemented a fabrication process utilizing PLL-g-PEG grafting on $\mathrm{SiO}_{2}$ substrates as shown in Figure 1. Prior to starting the patterning process, we set out to determine the highest PLL-g-PEG grafting density to achieve an effective non-fouling coating. We varied PLL-g-PEG concentration and incubation time and determined the optimal protocol based on minimum f-BSA adsorption (Figure S1a). Very high concentrations of the polymer lowered protein repulsion. This phenomenon can be attributed to the fact that in higher concentrations, chain entanglement and lower availability of adsorption sites per polymeric chain lead to a decrease in the adsorbed segment of a polymer chain and chain loop formation instead of adopting a flat conformation on the substrate. This in turn results in easier desorption and lower polymer density on the surface. ${ }^{45-48}$ Since patterning of PLL-g-PEG required brief acetone washing to remove photoresist (Figure 1A), the resistance of PLL-g-PEG coating to a 3 second exposure of acetone was evaluated. The acetone exposure did not result in a reduction in the non-fouling properties of PLL-g-PEG (Figure S1b), enabling us to move forward with the patterning process.

The developed coating protocol in the prior step was employed in combination with a photolithography process to generate the non-fouling micropattern. Two commonly used method for developing such a PLL-g-PEG pattern on our intended substrate are PDMS microcontact printing and deep UV laser ablation. ${ }^{24,31,38,49}$ Although microcontact printing is known to be simple and cost-effective, softness of the PDMS stamp which is necessary for suitable contact with the substrate results in vertical and lateral deformations which can affect the printed features and lead to stamp degradation after several patterning processes, particularly at our needed resolution. ${ }^{34-36}$ In addition, two-step ink transfer first to the stamp and then to the substrate reduces transfer efficiency and consistency of the pattern density and increases pattern defects especially when dealing with a comb co-polymer which only can be adsorbed from the backbone. ${ }^{34,37}$ Both mentioned complications can reduce reproducibility of the method for PLL-g-PEG patterning. On the other hand, laser ablation can provide a uniform reproducible coating on coated regions. ${ }^{24,38,39}$ However, determining the threshold for complete removal of the polymer without damaging the substrate can be challenging, and uncoated areas can also be covered by a low density of the patterning 
molecules with an incomplete ablation, which can decrease the resolution of the generated pattern. ${ }^{32,33,40,41}$ Therefore, we combined simple polymer surface adsorption and photolithography to make a reproducible pattern with high resolution in fewer steps. The patterning process results in a reliable production of PEG islands across the substrate. Environmental AFM measurements verified that the hydrated PLL-g-PEG molecules completely cover the patterned $3 \mu \mathrm{m}$ regions with minimal defects (Figure 1c and S2). The limited height of the hydrated PEG molecules which was less than $30 \mathrm{~nm}$ confirmed the process successfully resulted in a monolayer of PLL-g-PEG on the surface. The non-fouling nature of the PEG islands was visualized by incubating the substrate with f-BSA for $1 \mathrm{~h}$ and then washing (Figure 1d,e). The high-contrast green background with a regular pattern of black spots indicates f-BSA adsorbed to the $\mathrm{SiO}_{2}$ substrate everywhere except for the PEG islands. Multiple low magnification fluorescence images were taken in order to confirm faithful reproduction of the non-fouling pattern across large regions of the substrate. F-BSA coating confirmed that the developed non-fouling micropatterned substrate replicates the same disruption pattern of the pore openings in our previously utilized porous membranes, in which the PEG islands prevent protein adsorption just like the holes in the microporous membranes (Figure 1E).

\subsection{Cell Adhesion and Morphology on Continuous PLL-g-PEG Coating}

Our goal was to mimic the pore openings in a membrane using patterned PEG islands. To this end, it was necessary to confirm that our method for PLL-g-PEG coating provides a non-fouling surface not just for proteins, but also cells. In order to determine if the PEG coating could prevent cell attachment, we tested uniformly coated PLL-g-PEG substrates. The substrates were prepared using the same process as for patterned islands including acetone washing, but without photoresist. Cell culture on the uniform PEG substrates verified that this coating effectively prevents cell adhesion. HUVECs were seeded on $4 \times 4$ $\mathrm{mm}$ samples at a density of 6000 cells $/ \mathrm{cm}^{2}$ and imaged after $24 \mathrm{~h}$. While there was a slight increase in the number of cells counted on the control $\mathrm{SiO}_{2}$ substrates, almost no cells were found on the PEG coated substrates (Figure 2). The very limited number of cells found on the PEG coated substrates were always rounded with limited spreading compared to cells on the uncoated substrate (Figure 2a,b). Due to concerns about long-term stability of the PLLg-PEG coating, we pre-incubated samples for $24 \mathrm{~h}$ in cell culture media at $37^{\circ} \mathrm{C}$ prior to seeding cells. ${ }^{50,51}$ We found there was not a significant increase in the number of cells found on pre-incubated samples, indicating the PLL-g-PEG coating is stable for the duration of our experiments. These data confirm that the PLL-g-PEG coating reliably repels cell adhesion, mimicking the disruptive nature of pore openings.

\subsection{Cell Spreading and F-actin Quantification}

Cell spreading is a result of cell-substrate interactions, and is regulated by a variety of cellular processes. ${ }^{52-55}$ Actin stress fibers are ubiquitous in cell adhesion and mechanotransduction, and well-organized actin fibers correspond with successful cell adhesion. ${ }^{52,55,56}$ We evaluated cell adhesion on the non-fouling micropatterned substrates by investigating cell spreading and stress fiber formation. HUVECs were seeded on patterned substrates, and cells were stained using DAPI and Phalloidin after $24 \mathrm{~h}$ to visualize cell nuclei and stress fibers, respectively. We studied cell spreading as an indicator for cell- 
substrate interactions which is a competing factor during barrier formation as cells balance cell-cell and cell-substrate interactions. ${ }^{12,57}$ We believe spread area of individual cells is a better indicator of cell spreading capability, since the exact moment that the cell layer reaches confluency is not detectable and after that moment, cell area can be affected by cell density. Cell spreading was measured by determining borders of each cell manually in ImageJ software. Figure $3 \mathrm{c}$ shows cell size distribution after $24 \mathrm{~h}$ of spreading on the patterned and unpatterned $\mathrm{SiO}_{2}$ substrates. While mean cell area on $\mathrm{SiO} 2$ is around 1250 $\mu \mathrm{m}^{2}$, this value was drastically lower on PEG patterned samples. This cell size reduction can originate from the frequent disruption on the $\mathrm{SiO}_{2}$ substrate by PLL-g-PEG islands.

However, it was shown that the same pattern of disruption on $\mathrm{SiO}_{2}$ membranes by pores did not lead to a reduction in cell spreading. ${ }^{12}$ Mean fluorescent intensity of stained cytoskeleton using phalloidin in each cell was also measured using ImageJ to quantify factin on the patterned and unpatterned substrates. It was found that HUVECs form less factin on the disrupted surface of patterned substrates similarly to the previously investigated porous membranes ${ }^{12}$ (Figure $3 \mathrm{~d}$ ). The reduced cell spreading on the non-fouling micropatterns with the same pattern of surface disruption as our previous study suggests an additional factor must support cell spreading on porous membranes.

\subsection{Cell-cell interaction}

To investigate whether the surface disruption can promote cell-cell interaction and encourage barrier formation of the endothelial cells, we evaluated ZO-1 after $96 \mathrm{~h}$ following cell seeding on the PEG islands and control $\mathrm{SiO}_{2}$ substrates. $\mathrm{ZO}-1$ labeling was brighter and more continuous at cell borders on the micropatterned substrate as compared to the control substrates (Figure 3E and 3F). These data are consistent with our previous findings, where cells exhibited stronger ZO-1 labeling when cultured on porous membranes compared to continuous substrate controls. ${ }^{12}$ This is consistent with the notion that weakened cellsubstrate interactions promote stronger cell-cell interactions. ${ }^{12,57}$

\subsection{Cell Migration}

Cell migration is crucial in establishment of an endothelial barrier in a tissue-on-a-chip device or vascular graft. To study how substrate disruption affects cell motility and directionality and whether an additional factor is at play, we compared HUVEC migration on PEG patterned and unpatterned $\mathrm{SiO}_{2}$ substrates. Similarly to the prior studies, we investigated not only cell speed, but also the orientation or direction of cell migration between time-lapse images collected every 15 minutes over $24 \mathrm{~h}$ using a custom-written MATLAB algorithm (freely available on GitHub: https://github.com/gaborskilab). In these experiments, we used a far-red nuclear stain (SiR-Hoechst) that we have previously shown to have no effect on migratory behavior over long-term time-lapse imaging. ${ }^{44}$ As was noted earlier, cells on PEG patterned substrates spread significantly less than on control substrates. During time-lapse imaging it was also noted that some cells did not appear to fully attach and were incapable of migrating. Poorly adhered cells that did not migrate beyond a typical body width $(40 \mu \mathrm{m})$ within $24 \mathrm{~h}$ were excluded from further quantitative migratory analysis. This exclusion was not necessary in our prior studies on microporous membranes and again indicated that the disruption due to PEG islands, although similar to micropore openings, resulted in some distinctly different cellular behavior. 
The effect of substrate disruption on cell migration due to the PEG islands is most distinct when observing migration direction between time-lapse images. We defined each step of a cell's migratory trajectory based on the centroid of the nucleus from two successive images. The direction of these migration vectors indicated clear cellular preferences. We previously identified preferred sites of substrate interaction on the hexagonally micropatterned surface and labeled them as either A or B regions (Figure 4a), with three axes of symmetry. The cell steps in this study often aligned with the orientation of the A region, which closely resembles the cellular behavior on microporous substrates reported previously (Figure 4b). ${ }^{13}$

Using the same time-lapse images, we measured cell speed over $24 \mathrm{~h}$ on both PEG patterned and control substrates. Mean cell migration speed on the patterned substrates was marginally greater than that on the unpatterned substrates (Figure 4c). Cells on microporous $\mathrm{SiO}_{2}$ substrates also migrated faster than those on non-porous controls in our previous studies, but the differences were more striking. ${ }^{13}$ Taken together with the orientation data, it is clear that PEG patterning affects cell migration similarly to micropores. However, the impact of the PEG patterning on both orientation and cell speed compared to controls was less significant than that of micropores. While around $27.5 \%$ and $17.5 \%$ of the steps were toward the A and B directions on the micropatterned substrates, more than $36 \%$ of the steps were toward the A direction and only $13.5 \%$ of the steps were toward B on the porous membranes. There was a more striking difference between migration toward A or B on the porous membranes as compared to steps on the PEG islands. Additionally, the increased migration toward the intersection between A and B on the PEG islands also suggests that there is less polarization toward direction A on these substrates as compared to the previous substrates. This implies that cell-substrate disruption due to PEG islands and pore openings was only one factor affecting migratory behavior.

\subsection{Fibronectin Fibrillogenesis}

Our previous studies concluded that the discontinuity of microporous membranes disrupted cell-substrate interactions, negatively impacting FN fibrillogenesis. ${ }^{12,13}$ Others have described that FN fibrils preferentially form when tension is generated along a FN-substrate tether. ${ }^{58}$ We hypothesized that PEG islands would replicate the disruption of the micropore openings. Here, like in our previous studies, we investigated fibronectin fibrillogenesis after $24 \mathrm{~h}$ on PEG patterned and unpatterned $\mathrm{SiO}_{2}$ substrates. Substrates were uncoated, with the only source of FN being that secreted by the cells or soluble FN in the culture media. Lengths of fibrils were measured using a custom-written MATLAB algorithm (freely available on GitHub: https://github.com/gaborskilab). Similarly to microporous substrates ${ }^{12,13}$, fibronectin fibril length was significantly shorter on PEG patterned $\mathrm{SiO}_{2}$ with a mean length of $3.2 \mu \mathrm{m}$ compared to $5.9 \mu \mathrm{m}$ on unpatterned $\mathrm{SiO}_{2}$ (Figure 5).

\subsection{Comparison Between PEG-Patterned and Porous $\mathrm{SiO}_{2}$ Substrates}

Cellular behavior on our non-fouling PEG micropattern had some similarities, but several distinct differences from behavior on membranes with micropores of identical size and placement in our previous studies. ${ }^{12,13}$ Our intent was to recreate the cell-substrate disruptions resulting from the physical openings or void spaces of a microporous membrane. We deposited a dense and complete carpet of PLL-g-PEG within a micropattern that 
selectively prevented protein adsorption and therefore cell attachment within the targeted pore-like regions. The similarities in cellular responses confirm that disruption of cellsubstrate interactions is likely a major factor in the cell's response to a porous membrane. Some of the differences in behavior, including differences in enhancement of migration speed, suggests there is an additional factor that contributes to cellular behavior over micropores. Due to the thinness and non-fouling ${ }^{30}$ nature of the PEG coating (Figure 1E and 2), we expect that PLL-g-PEG islands do not provide any obstacles nor enable any interactions for the cell. Micropores on the other hand, have distinct edges and pore walls that the cell likely feels as it adheres and migrates over a substrate. The pore edges and walls have the same physical and chemical properties as the planar surface and may offer additional substrate interactions.

We expected that discontinuity in the cell-substrate interaction through micropatterning of non-fouling PEG islands would weaken cell attachment and spreading. Indeed, we report roughly $30 \%$ reduction in HUVEC spread area over PEG islands compared to unpatterned controls (Figure 6b). Interestingly, spread area did not decrease in our previous study on microporous membranes. ${ }^{12}$ This indicates that some aspect of the pores presents a positive factor that improves cell spreading, and therefore, negates the loss in cell area due to surface discontinuity. During investigation of cell motility, speed was only marginally faster over PEG islands compared to controls ( 3\%), whereas microporous substrates offered a nearly $15 \%$ increase in cell speed (Figure $6 \mathrm{c}$ ). The difference in magnitude of migration speed further points to the idea that additional physical factors of the micropores potentially enhances cellular grip on the substrate, while the disruption may prime the cell for motility by discouraging strong and more permanent cell-substrate adhesion. ${ }^{12}$

The nearly equal trend of reduction in FN fibril length over PEG islands and micropores, ${ }^{13}$ as compared to their respective controls, indicates that the pore edges are not beneficial for fibrillogenesis. Pore edges and walls provide increased substrate contact area, which could have offered additional FN tethering sites, and the increased spread area and cell speed suggest cells over micropores are able to generate higher traction forces and increased actin polymerization, which have been shown to be positively correlated with FN fibrillogenesis. 59,60 However, the discontinuity of a substrate due to PEG islands or micropores may dictate where fibrillogenesis occurs and dominate the cellular response. In our previous work, a membrane with sub-micron pores had even shorter FN fibrils than the microporous membrane. The sub-micron porous membrane had less inter-pore spacing and therefore more discontinuity, but a greater number of pore edges. These data suggest that vertical pore walls may present a non-ideal placement of integrins for fibrillogenesis, but may still benefit cell spreading and migration (Figure 7).

\section{CONCLUSIONS}

This study set out to determine the impact of micron-scale contact-free domains on cellsubstrate interactions. Previous work showed that pores in cell culture membranes had significant impact on cellular behavior, including substrate adhesion, ECM production, and migration. ${ }^{12,13,21}$ We hypothesized that the altered behavior may be due to more than just the cell-substrate disruptions over the pore openings. Here we patterned $\mathrm{SiO}_{2}$ substrates with 
micron-scale non-fouling PEG islands that mimicked pore openings, with identical size and pattern to previously studied porous membranes. We specifically designed the substrates to have the same physical and chemical properties in an identical fabrication process, with the only difference being the way they disrupted cell-substrate interactions. We found that while some cell-substrate interactions were disrupted on patterned substrates similarly to our previous findings on porous membranes, there were also clear differences. Our data, as compared to our previous studies, suggests that membrane pores not only disrupt cellsubstrate interactions, but also provide additional physical factors that affect cellular responses compared to non-fouling domains alone. These results provide a more complete picture on how porous membranes affect the cells which are grown on them in an increasing number of cellular barrier and co-culture studies. This understanding can help advance two areas of research. First, we demonstrated that micron-scale surface disruption weakens cellsubstrate interactions on stiff substrates, similarly to what has been shown for soft substrates. This knowledge could be beneficial in biomanufacturing and substrate induced stem cell differentiation, where large-scale patterned or porous substrates could replace soft materials currently used in research. Second, the differences in cellular behavior on patterned PEG substrates and porous membranes could help elucidate the interplay between cell migration and ECM fibrillogenesis. For instance, future studies could investigate whether increased vertical contact area, with thicker membranes, leads to further increases in cell migration while maintaining stable ECM production, decoupling these processes from one another.

\title{
Supplementary Material
}

Refer to Web version on PubMed Central for supplementary material.

\section{ACKNOWLEDGEMENTS}

\author{
We thank Sean O’Brien from Semiconductor \& Microsystems Fabrication Laboratory (SMFL) at Rochester \\ Institute of Technology for assistance with photolithography. \\ Funding Sources \\ Research reported in this publication was supported by NIGMS of the National Institutes of Health under award \\ number R35GM119623 to TRG
}

\section{REFERENCES}

(1). Bhatia SN; Ingber DE Microfluidic Organs-on-Chips. Nature Biotechnology. Nature Publishing Group 8 1, 2014, pp 760-772. 10.1038/nbt.2989.

(2). Chung HH; Mireles M; Kwarta BJ; Gaborski TR Use of Porous Membranes in Tissue Barrier and Co-Culture Models. Lab Chip 2018, 18 (12), 1671-1689. 10.1039/C7LC01248A. [PubMed: 29845145]

(3). Huh D; Matthews BD; Mammoto A; Montoya-Zavala M; Hsin HY; Ingber DE Reconstituting Organ-Level Lung Functions on a Chip. Science 2010, 328 (5986), 1662-1668. 10.1126/ science.1188302. [PubMed: 20576885]

(4). Booth R; Kim H Characterization of a Microfluidic in Vitro Model of the Blood-Brain Barrier (MBBB). Lab Chip 2012, 12 (10), 1784 10.1039/c2lc40094d. [PubMed: 22422217]

(5). Ma SH; Lepak LA; Hussain RJ; Shain W; Shuler ML An Endothelial and Astrocyte Co-Culture Model of the Blood-Brain Barrier Utilizing an Ultra-Thin, Nanofabricated Silicon Nitride Membrane. Lab Chip 2005, 5 (1), 74-85. 10.1039/B405713A. [PubMed: 15616743] 
(6). Jang K-J; Mehr AP; Hamilton GA; McPartlin LA; Chung S; Suh K-Y; Ingber DE Human Kidney Proximal Tubule-on-a-Chip for Drug Transport and Nephrotoxicity Assessment. Integr. Biol 2013, 5 (9), 1119-1129. 10.1039/c3ib40049b.

(7). Wang Z; Teoh SH; Hong M; Luo F; Teo EY; Chan JKY; Thian ES Dual-Microstructured Porous, Anisotropic Film for Biomimicking of Endothelial Basement Membrane. ACS Appl. Mater. Interfaces 2015, 7 (24), 13445-13456. 10.1021/acsami.5b02464. [PubMed: 26030777]

(8). Mazzocchi AR; Man AJ; DesOrmeaux J-PS; Gaborski TR Porous Membranes Promote Endothelial Differentiation of Adipose-Derived Stem Cells and Perivascular Interactions. Cell. Mol. Bioeng 2014, 7 (3), 369-378. 10.1007/s12195-014-0354-7.

(9). Pensabene V; Costa L; Terekhov AY; Gnecco JS; Wikswo JP; Hofmeister WH Ultrathin Polymer Membranes with Patterned, Micrometric Pores for Organs-on-Chips. ACS Appl. Mater. Interfaces 2016, 8 (34), 22629-22636. 10.1021/acsami.6b05754. [PubMed: 27513606]

(10). Kim HJ; Huh D; Hamilton G; Ingber DE Human Gut-on-a-Chip Inhabited by Microbial Flora That Experiences Intestinal Peristalsis-like Motions and Flow. Lab Chip 2012, 12 (12), 2165 10.1039/c2lc40074j. [PubMed: 22434367]

(11). Granitzny A; Knebel J; Müller M; Braun A; Steinberg P; Dasenbrock C; Hansen T Evaluation of a Human in Vitro Hepatocyte-NPC Co-Culture Model for the Prediction of Idiosyncratic DrugInduced Liver Injury: A Pilot Study. Toxicol. Reports 2017, 4, 89-103. 10.1016/ J.TOXREP.2017.02.001.

(12). Casillo SM; Peredo AP; Perry SJ; Chung HH; Gaborski TR Membrane Pore Spacing Can Modulate Endothelial Cell-Substrate and Cell-Cell Interactions. ACS Biomater. Sci. Eng 2017, 3 (3), 243-248. 10.1021/acsbiomaterials.7b00055. [PubMed: 28993815]

(13). Chung HH; Casillo SM; Perry SJ; Gaborski TR Porous Substrates Promote Endothelial Migration at the Expense of Fibronectin Fibrillogenesis. ACS Biomater. Sci. Eng 2018, 4 (1), 222-230. 10.1021/acsbiomaterials.7b00792. [PubMed: 29713681]

(14). Sochol RD, Higa AT, Janairo RRR, Li S, \& Lin L Microscale Control of Micropost Stiffness to Induce Cellular Durotaxis. In Twelfth International Conference on Miniaturized Systems for Chemistry and Life Sciences; 2008; pp 1335-1337.

(15). Sochol RD; Higa AT; Janairo RRR; Li S; Lin L Effects of Micropost Spacing and Stiffness on Cell Motility. Micro Nano Lett. 2011, 6 (5), 323 10.1049/mnl.2011.0020.

(16). Fu J; Wang Y-K; Yang MT; Desai RA; Yu X; Liu Z; Chen CS Mechanical Regulation of Cell Function with Geometrically Modulated Elastomeric Substrates. Nat. Methods 2010, 7 (9), $733-$ 736. 10.1038/nmeth.1487. [PubMed: 20676108]

(17). Han SJ; Bielawski KS; Ting LH; Rodriguez ML; Sniadecki NJ Decoupling Substrate Stiffness, Spread Area, and Micropost Density: A Close Spatial Relationship between Traction Forces and Focal Adhesions. Biophys. J 2012, 103 (4), 640-648. 10.1016/J.BPJ.2012.07.023. [PubMed: 22947925]

(18). Sochol RD; Higa AT; Janairo RRR; Li S; Lin L Unidirectional Mechanical Cellular Stimuli via Micropost Array Gradients. Soft Matter 2011, 7 (10), 4606 10.1039/c1sm05163f.

(19). Takeshita Y; Obermeier B; Cotleur A; Sano Y; Kanda T; Ransohoff RM An in Vitro Blood-Brain Barrier Model Combining Shear Stress and Endothelial Cell/Astrocyte Co-Culture. J. Neurosci. Methods 2014, 232, 165-172. 10.1016/J.JNEUMETH.2014.05.013. [PubMed: 24858797]

(20). Kukulski F; Ben Yebdri F; Lefebvre J; Warny M; Tessier PA; Sévigny J Extracellular Nucleotides Mediate LPS-Induced Neutrophil Migration in Vitro and in Vivo. J. Leukoc. Biol 2007, 81 (5), 1269-1275. 10.1189/jlb.1206758. [PubMed: 17322022]

(21). Salminen AT; Zhang J; Madejski GR; Khire TS; Waugh RE; McGrath JL; Gaborski TR Ultrathin Dual-Scale Nano- and Microporous Membranes for Vascular Transmigration Models. Small 2019, 15 (6), 1804111 10.1002/smll.201804111.

(22). Prabhakarpandian B; Shen M-C; Nichols JB; Mills IR; Sidoryk-Wegrzynowicz M; Aschner M; Pant K SyM-BBB: A Microfluidic Blood Brain Barrier Model. Lab Chip 2013, 13 (6), 1093 10.1039/c2lc41208j. [PubMed: 23344641]

(23). Falconnet D, Pasqui D, Park S, Eckert R, Schift H, Gobrecht J, Barbucci J, \& Textor M A Novel Approach to Produce Protein Nanopatterns by Combining Nanoimprint Lithography and Molecular Self-Assembly. Nano Lett. 2004, 4 (10), 1909-1914. 10.1021/NL0489438. 
(24). Azioune A; Carpi N; Tseng Q; Théry M; Piel M Protein Micropatterns: A Direct Printing Protocol Using Deep UVs. Methods Cell Biol. 2010, 97, 133-146. 10.1016/ S0091-679X(10)97008-8. [PubMed: 20719269]

(25). Vignaud T; Galland R; Tseng Q; Blanchoin L; Colombelli J; Théry M Reprogramming Cell Shape with Laser Nano-Patterning. J. Cell Sci 2012, 125 (Pt 9), 2134-2140. 10.1242/jcs.104901. [PubMed: 22357956]

(26). Rothenberg KE; Neibart SS; LaCroix AS; Hoffman BD Controlling Cell Geometry Affects the Spatial Distribution of Load Across Vinculin. Cell. Mol. Bioeng 2015, 8 (3), 364-382. 10.1007/ s12195-015-0404-9.

(27). Liu W-D; Yang B Patterned Surfaces for Biological Applications: A New Platform Using Two Dimensional Structures as Biomaterials. Chinese Chem. Lett 2017, 28 (4), 675-690. 10.1016/ J.CCLET.2016.09.004.

(28). Michel R, Lussi JW, Csucs G, Reviakine I, Danuser G, Ketterer B, .. \& Spencer ND Selective Molecular Assembly Patterning: A New Approach to Micro- and Nanochemical Patterning of Surfaces for Biological Applications. Langmuir 2002, 18 (8), 3281-3287. 10.1021/LA011715Y.

(29). Marie R; Dahlin AB; Tegenfeldt JO; Höök F Generic Surface Modification Strategy for Sensing Applications Based on $\mathrm{Au} / \mathrm{SiO}_{2}$ Nanostructures. Biointerphases 2007, 2 (1), 49-55. 10.1116/1.2717926. [PubMed: 20408636]

(30). Lussi JW; Falconnet D; Hubbell JA; Textor M; Csucs G Pattern Stability under Cell Culture Conditions-A Comparative Study of Patterning Methods Based on PLL-g-PEG Background Passivation. Biomaterials 2006, 27 (12), 2534-2541. 10.1016/J.BIOMATERIALS.2005.11.027. [PubMed: 16364431]

(31). Csucs G; Michel R; Lussi JW; Textor M; Danuser G Microcontact Printing of Novel CoPolymers in Combination with Proteins for Cell-Biological Applications. Biomaterials 2003, 24 (10), 1713-1720. 10.1016/S0142-9612(02)00568-9. [PubMed: 12593952]

(32). Ihlemann J Patterning of Oxide Thin Films by UV-Laser Ablation. J. Optoelectron. Adv. Mater 2005, 7 (3), 1191-1195.

(33). Musaev OR; Scott P; Wrobel JM; Wolf JA; Kruger MB UV Laser Ablation of Parylene Films from Gold Substrates. J. Mater. Sci 2011, 46 (1), 183-187. 10.1007/s10853-010-4906-5.

(34). Falconnet D; Csucs G; Michelle Grandin H; Textor M Surface Engineering Approaches to Micropattern Surfaces for Cell-Based Assays. Biomaterials 2006, 27 (16), 3044-3063. 10.1016/ J.BIOMATERIALS.2005.12.024. [PubMed: 16458351]

(35). Hui CY, Jagota A, Lin YY, Kramer EJ Constraints on Microcontact Printing Imposed by Stamp Deformation. Langmuir 2002, 18 (4), 1394-1407. 10.1021/LA0113567.

(36). Huang YY, Zhou W, Hsia KJ, Menard E, Park JU, Rogers JA, \& Alleyne AG Stamp Collapse in Soft Lithography. Langmuir 2005, 21 (17). 10.1021/LA0502185.

(37). Perl A; Reinhoudt DN; Huskens J Microcontact Printing: Limitations and Achievements. Adv. Mater 2009, 21 (22), 2257-2268. 10.1002/adma.200801864.

(38). Azioune A; Storch M; Bornens M; Théry M; Piel M Simple and Rapid Process for Single Cell Micro-Patterning. Lab Chip 2009, 9 (11), 1640 10.1039/b821581m. [PubMed: 19458875]

(39). Thissen H; Hayes JP; Kingshott P; Johnson G; Harvey EC; Griesser HJ Nanometer Thickness Laser Ablation for Spatial Control of Cell Attachment. Smart Mater. Struct 2002, 11 (5), 792799. 10.1088/0964-1726/11/5/326.

(40). Dyer PE Excimer Laser Polymer Ablation: Twenty Years On. Appl. Phys. A 2003, 77 (2), $167-$ 173. 10.1007/s00339-003-2137-1.

(41). Jeon H; Schmidt R; Barton JE; Hwang DJ; Gamble LJ; Castner DG; Grigoropoulos CP; Healy KE Chemical Patterning of Ultrathin Polymer Films by Direct-Write Multiphoton Lithography. J. Am. Chem. Soc 2011, 133 (16), 6138-6141. 10.1021/ja200313q. [PubMed: 21452872]

(42). Carter RN; Casillo SM; Mazzocchi AR; DesOrmeaux J-PS; Roussie JA; Gaborski TR Ultrathin Transparent Membranes for Cellular Barrier and Co-Culture Models. Biofabrication 2017, 9 (1), 015019 10.1088/1758-5090/aa5ba7. [PubMed: 28140345]

(43). Müller M; Lee S; Spikes HA; Spencer ND The Influence of Molecular Architecture on the Macroscopic Lubrication Properties of the Brush-Like Co-Polyelectrolyte Poly(L-Lysine)- $g$ - 
Poly(Ethylene Glycol) (PLL- $g$-PEG) Adsorbed on Oxide Surfaces. Tribol. Lett 2003, 15 (4), 395-405. 10.1023/B:TRIL.0000003063.98583.bb.

(44). Chung HH; Bellefeuille SD; Miller HN; Gaborski TR Extended Live-Tracking and Quantitative Characterization of Wound Healing and Cell Migration with SiR-Hoechst. Exp. Cell Res 2018, 373 (1-2), 198-210. 10.1016/J.YEXCR.2018.10.014. [PubMed: 30399373]

(45). Lin Y-H In Polymer Viscoelasticity: Basics, Molecular Theories and Experiments.; WORLD SCIENTIFIC, 2010 10.1142/7786.

(46). Furusawa K; Yamamoto K Competitive Effects in Polymer Adsorption and Exchangeability of Adsorption Layer. Bull. Chem. Soc. Jpn 1983, 56 (7), 1958-1962. 10.1246/bcsj.56.1958.

(47). Sperling LH Polymer Surfaces and Interfaces: The Need for Uniform Terminology. ACS Div. Polym. Mater. Sci. Eng 1995.

(48). Jiménez-Pardo I; van der Ven L; van Benthem R; de With G; Esteves A; Jiménez-Pardo I; Van der Ven LGJ; Van Benthem RATM; De With G; Esteves ACC Hydrophilic Self-Replenishing Coatings with Long-Term Water Stability for Anti-Fouling Applications. Coatings 2018, 8 (5), 184 10.3390/coatings8050184.

(49). Ochsner M; Dusseiller MR; Grandin HM; Luna-Morris S; Textor M; Vogel V; Smith ML MicroWell Arrays for 3D Shape Control and High Resolution Analysis of Single Cells. Lab Chip 2007, 7 (8), 1074 10.1039/b704449f. [PubMed: 17653351]

(50). Chen Y; Pidhatika B; von Erlach T; Konradi R; Textor M; Hall H; Lühmann T Comparative Assessment of the Stability of Nonfouling Poly(2-Methyl-2-Oxazoline) and Poly(Ethylene Glycol) Surface Films: An in Vitro Cell Culture Study. Biointerphases 2014, 9 (3), 031003 10.1116/1.4878461. [PubMed: 25280844]

(51). Nelson CM, Raghavan S, Tan JL, \& Chen CS Degradation of Micropatterned Surfaces by CellDependent and -Independent Processes $\dagger$. Langmuir 2003, 19 (5), 1493-1499. 10.1021/ LA026178B.

(52). Yeung T; Georges PC; Flanagan LA; Marg B; Ortiz M; Funaki M; Zahir N; Ming W; Weaver V; Janmey PA Effects of Substrate Stiffness on Cell Morphology, Cytoskeletal Structure, and Adhesion. Cell Motil. Cytoskeleton 2005, 60 (1), 24-34. 10.1002/cm.20041. [PubMed: 15573414]

(53). Discher DE; Janmey P; Wang Y-L Tissue Cells Feel and Respond to the Stiffness of Their Substrate. Science 2005, 310 (5751), 1139-1143. 10.1126/science.1116995. [PubMed: 16293750]

(54). Pelham RJ; Wang Y.1. Cell Locomotion and Focal Adhesions Are Regulated by Substrate Flexibility. Proc. Natl. Acad. Sci. U. S. A 1997, 94 (25), 13661-13665. 10.1073/ PNAS.94.25.13661. [PubMed: 9391082]

(55). Cavalcanti-Adam EA; Micoulet A; Blümmel J; Auernheimer J; Kessler H; Spatz JP Lateral Spacing of Integrin Ligands Influences Cell Spreading and Focal Adhesion Assembly. Eur. J. Cell Biol 2006, 85 (3-4), 219-224. 10.1016/J.EJCB.2005.09.011. [PubMed: 16546564]

(56). Tojkander S; Gateva G; Lappalainen P Actin Stress Fibers--Assembly, Dynamics and Biological Roles. J. Cell Sci 2012, 125 (Pt 8), 1855-1864. 10.1242/jcs.098087. [PubMed: 22544950]

(57). Guo W; Frey MT; Burnham NA; Wang Y Substrate Rigidity Regulates the Formation and Maintenance of Tissues. Biophys. J 2006, 90 (6), 2213-2220. 10.1529/BIOPHYSJ.105.070144. [PubMed: 16387786]

(58). Singh P; Carraher C; Schwarzbauer JE Assembly of Fibronectin Extracellular Matrix. Annu. Rev. Cell Dev. Biol 2010, 26, 397-419. 10.1146/annurev-cellbio-100109-104020. [PubMed: 20690820]

(59). Lemmon CA; Chen CS; Romer LH Cell Traction Forces Direct Fibronectin Matrix Assembly. Biophys. J 2009, 96 (2), 729-738. 10.1016/J.BPJ.2008.10.009. [PubMed: 19167317]

(60). Eisenberg JL; Safi A; Wei X; Espinosa HD; Budinger GS; Takawira D; Hopkinson SB; Jones JC Substrate Stiffness Regulates Extracellular Matrix Deposition by Alveolar Epithelial Cells. Res. Rep. Biol 2011, 2011 (2), 1-12. 10.2147/RRB.S13178. [PubMed: 23204878] 
A
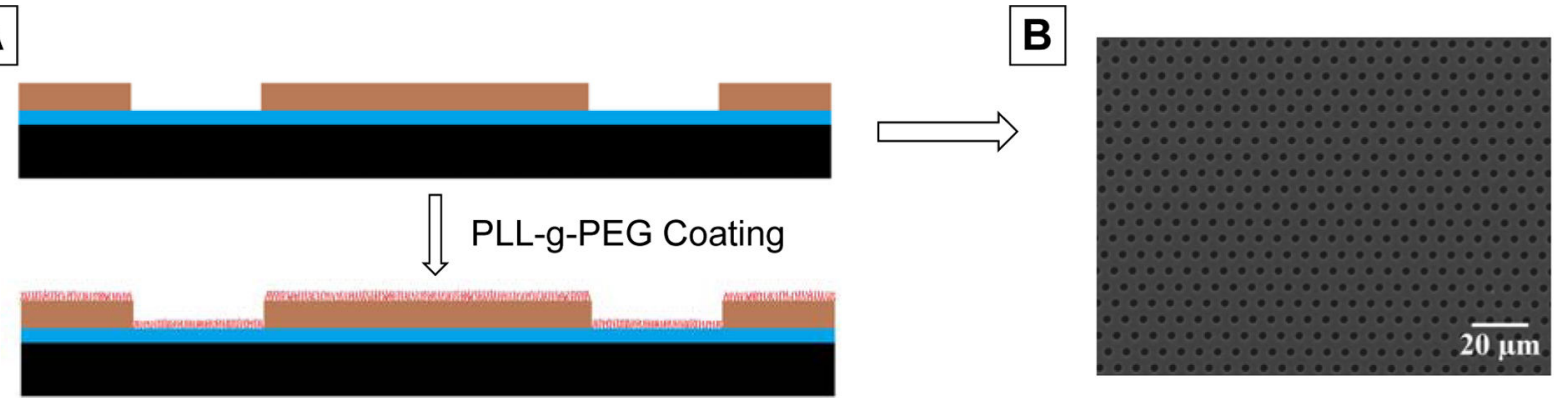

Acetone Washing

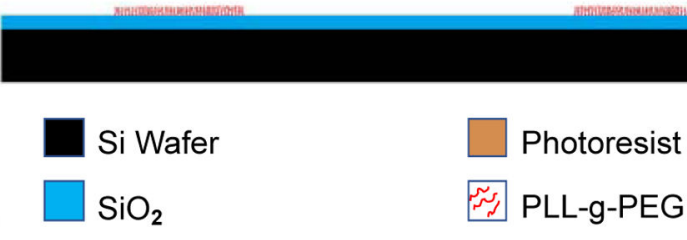

D
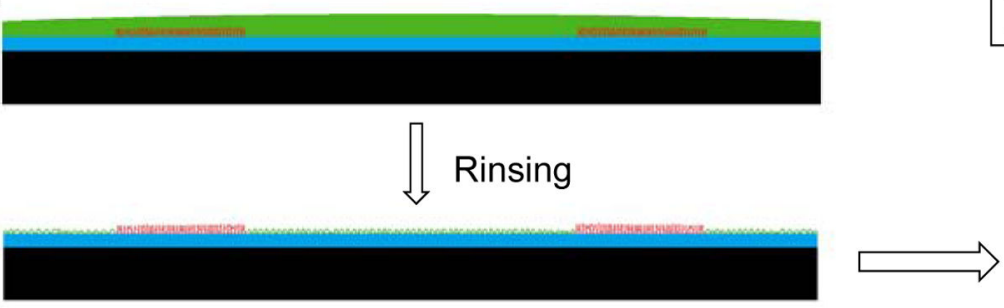

C

Si Wafer

$f-B S A$

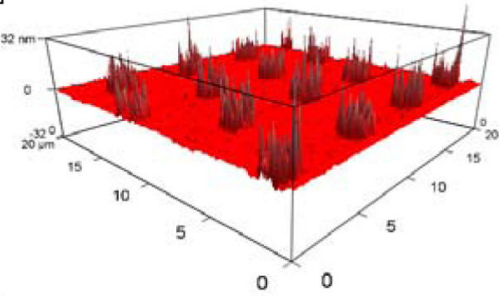

E

$\mathrm{SiO}_{2}$

PLL-g-PEG

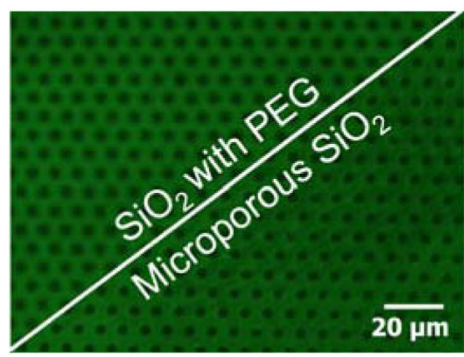

Figure 1.

(A) Schematic illustration of preparation steps for PLL-g-PEG patterning. (B) SEM image of the surface after photolithography. (C) AFM height profile of the PLL-g-PEG-patterned substrate. (D) Process design of patterning visualization using f-BSA. (E) Visualization of the final non-fouling micropattern using f-BSA as compared to the f-BSA coated microporous membrane. 

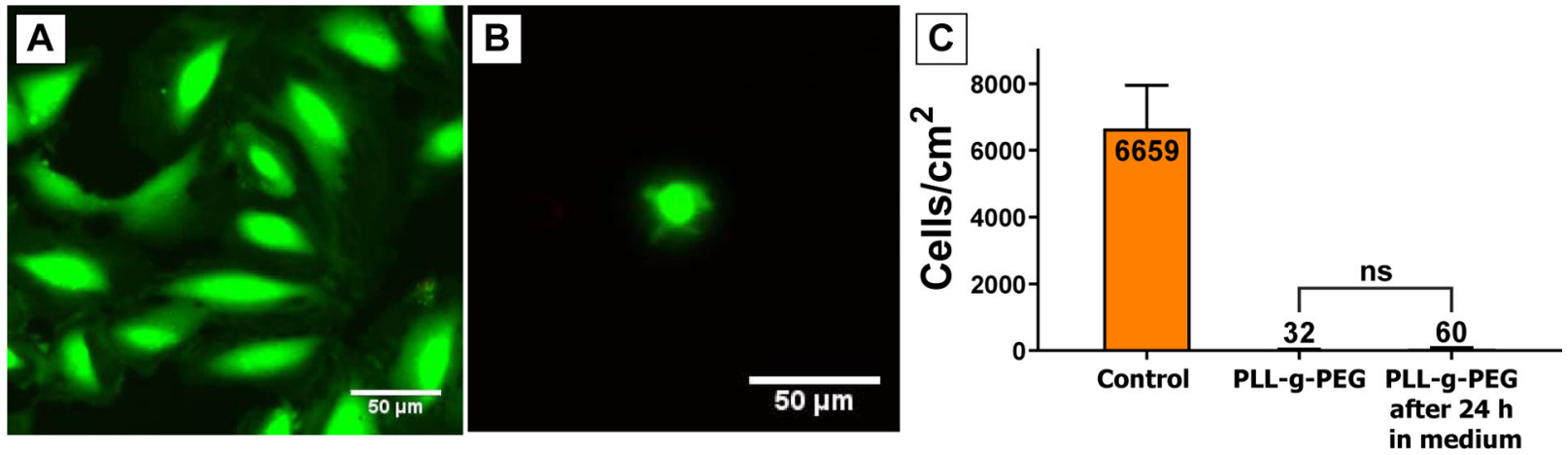

Figure 2.

Representative images of Live/Dead staining on (A) Control $\mathrm{SiO}_{2}$, and (B) fully PLL-g-PEG coated $\mathrm{SiO}_{2}$ after $24 \mathrm{~h}$ of cell seeding. (C) Cell density on the control $\mathrm{SiO}_{2}$, the fully PLL-gPEG coated $\mathrm{SiO}_{2}$, and the incubated fully PLL-g-PEG coated $\mathrm{SiO}_{2}$ after $24 \mathrm{~h}$ of cell culture. $(n>7$ independent substrates for each condition) 

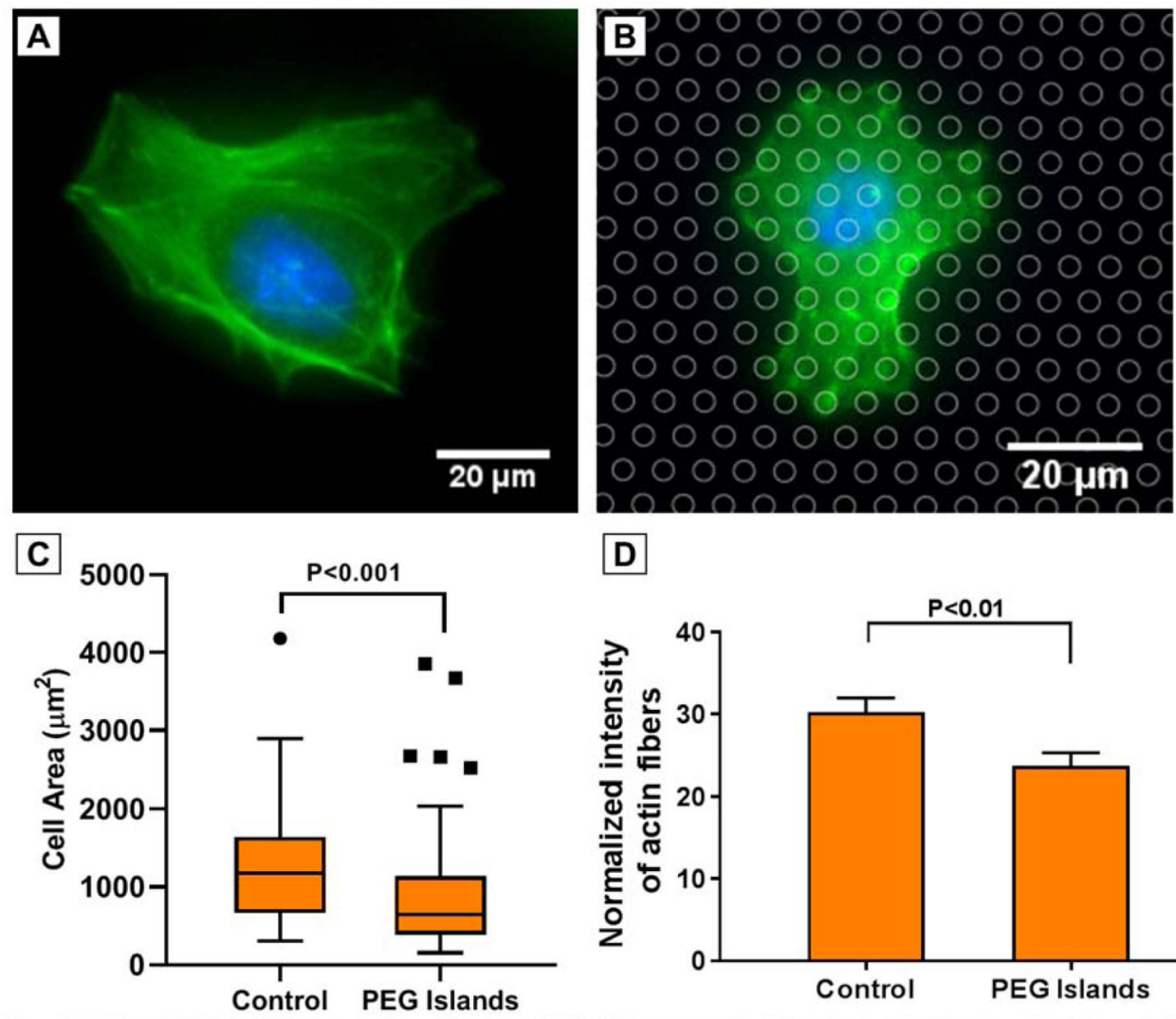

D
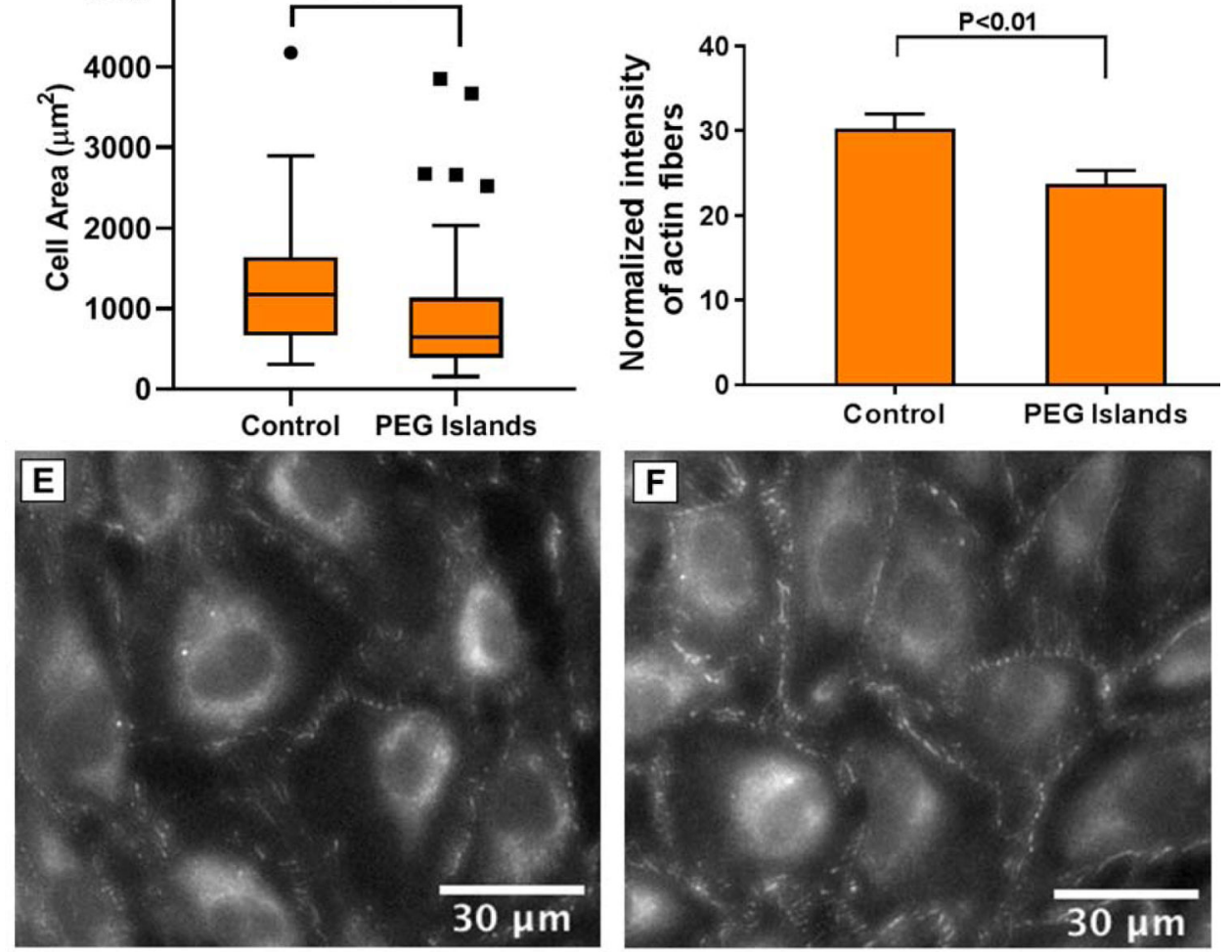

Figure 3.

Representative images of nuclei (DAPI, blue), and F-actin (phalloidin, green) after $24 \mathrm{~h}$ on (A) Control $\mathrm{SiO}_{2}$, and (B) PEG Islands. PEG islands are indicated by circles on the image $\mathrm{B}$. (C, D) Cell area and Normalized intensity of F-actin, respectively. ( $\mathrm{n}>11$ substrates; $>77$ cells for each condition). (E, F) Representative images of ZO1 staining after $96 \mathrm{~h}$ on Control $\mathrm{SiO}_{2}$, and PEG Islands, respectively. 
A

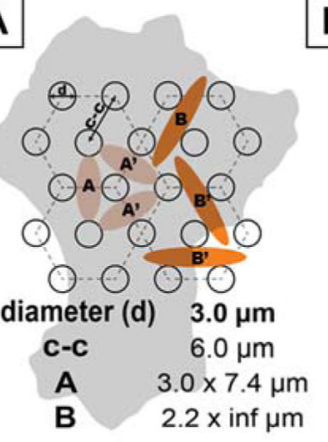

B

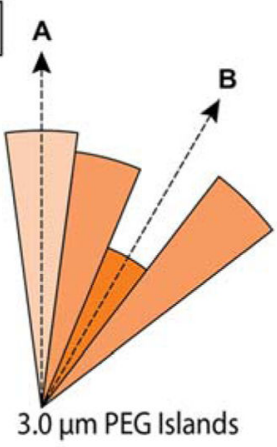

A

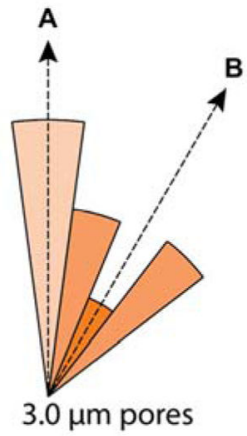

C

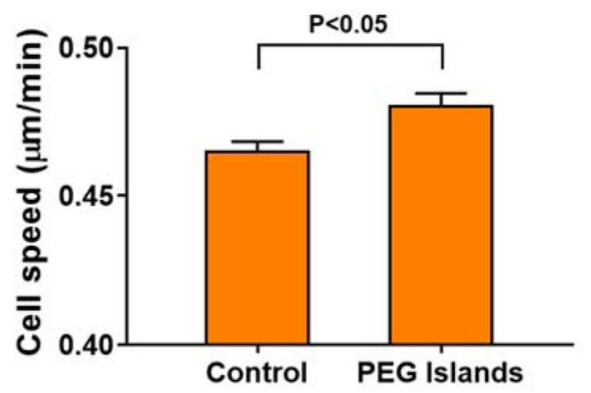

Figure 4.

(A) Schematic illustration of the PEG island spacing and potential regions for fibronectin fibril initiations. (B) Radial histogram of the step directions for cell migration on the substrates with $3 \mu \mathrm{m}$ PEG islands vs. $3 \mu \mathrm{m}$ pores. ( $\mathrm{n}>400$ cells; > 12000 steps); The histogram for $3 \mu \mathrm{m}$ pores is from Chung et. al. ${ }^{13}$ (C) Speed of migration on PEG islands vs. Control $\mathrm{SiO}_{2}$. $(\mathrm{n}=4$ substrates for each condition; > 1000 cells). 

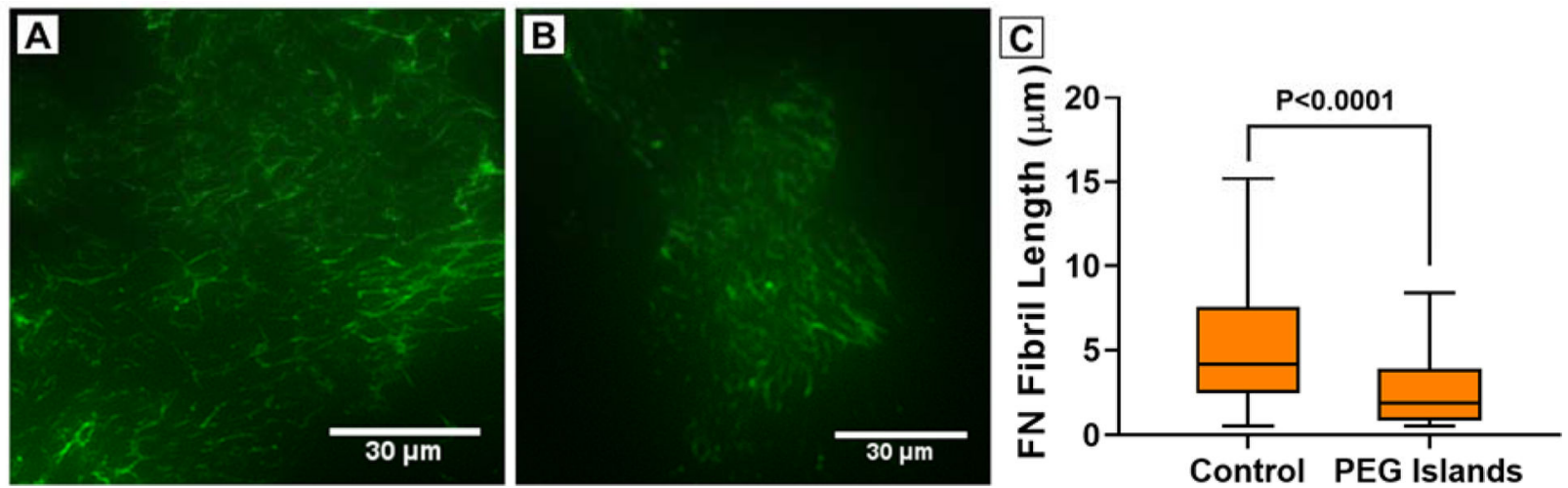

Figure 5.

Representative images of fibronectin fibrillogenesis on (A) Control $\mathrm{SiO}_{2}$, and (B) PEG

Islands. (C) Distribution of fibronectin fibrils lengths on Control $\mathrm{SiO}_{2}$, and PEG islands. (n $>5$ substrates for each condition; > 3600 fibers) 
A
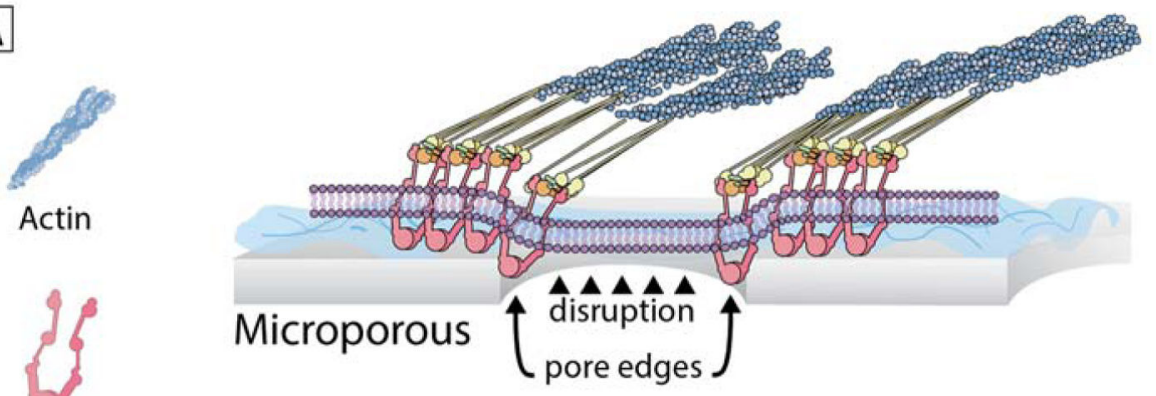

Integrin

Fibronectin

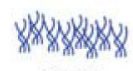

PEG

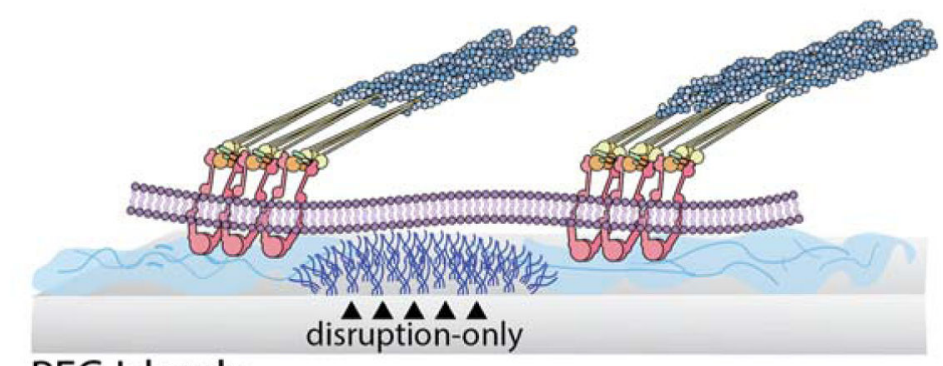

PEG Islands

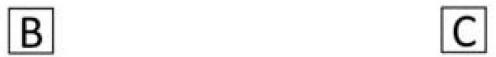

D
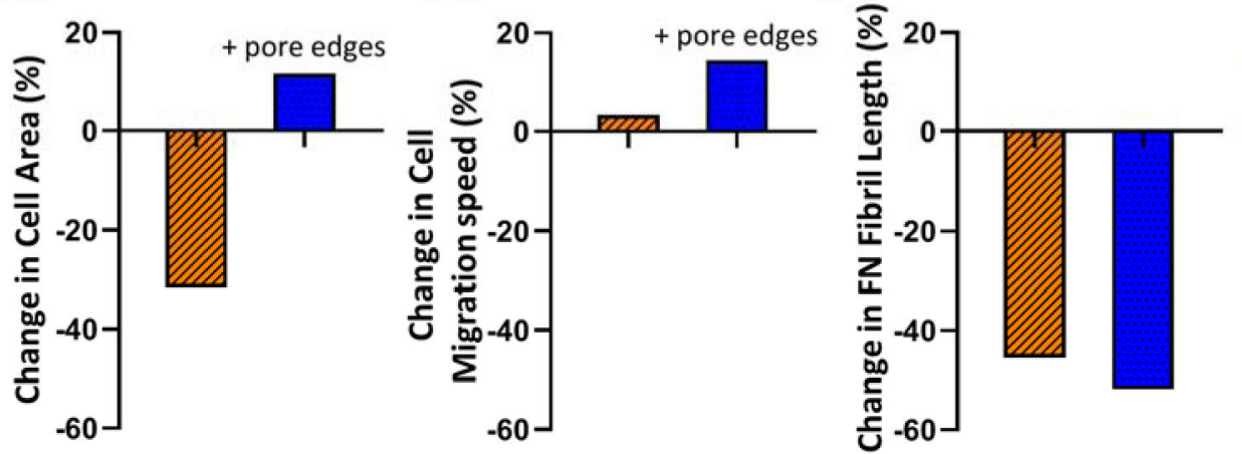

$3 \mu \mathrm{m}$ PEG Islands

$3 \mu \mathrm{m}$ Pores

Figure 6.

(A) Illustration showing PEG islands disrupt cell-substrate interactions similarly to pore openings, while porous membranes have additional physical characteristics. (B-D)

Comparative cellular behavior between $3 \mu \mathrm{m}$ PEG islands and $3 \mu \mathrm{m}$ pores, including (B) change in cell spread area, (C) change in cell migration speed, and (D) change in fibronectin fibril length relative to unpatterned and non-porous controls. Data on PEG islands and micropores were normalized with respect to their own controls. $3 \mu \mathrm{m}$ Pores data is analyzed from Casillo et al. and Chung et. al. ${ }^{12,13}$ 